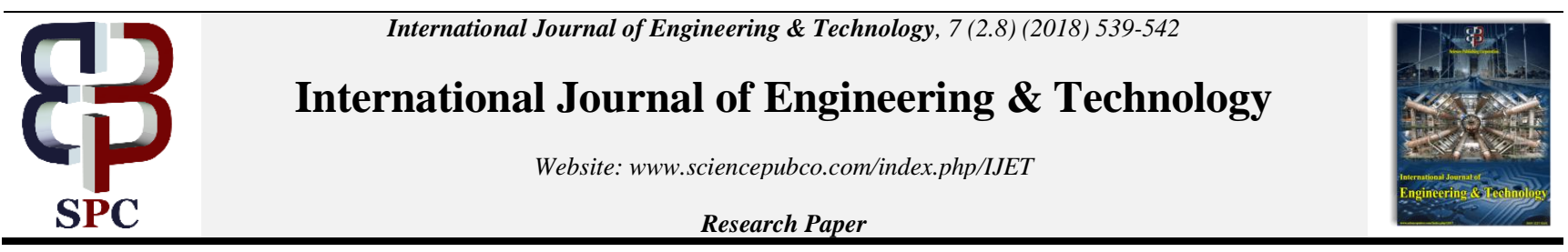

\title{
Analysis of exhaust manifold to improve the engine performance
}

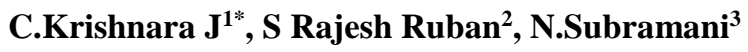 \\ ${ }^{1}$ Professor, Karpagam College of Engineering, Coimbatore. \\ ${ }^{2}$ Assistant Professor, Karunya Institute of Technology and Sciences, Coimbatore- 641114 \\ ${ }^{3}$ Assistant Professor, Karpagam College of Engineering, Coimbatore- 641032 \\ *Corresponding Author Email: krishna.kce@gmail.com
}

\begin{abstract}
The aim of the work is to analyze the performance of the engine exhaust manifold. Because the engine exhaust manifold is a significant factor in the engine performance. In this work the manifold design is prepared with the help of CAD software and it is analyzed by the ANSYS. This CFD and thermal analysis also done to check the performance of the redesigned exhaust manifold. The aim of CFD simulations performed to investigate the volumetric efficiency behaviour of an exhaust.
\end{abstract}

Keywords: Engine Performance, Exhaust Manifold, Emission and Fuel Consumption.

\section{Introduction}

The mounted exhaust manifolds on top of the cylinder head of the engine collect the gas exhausted from the engine, and sends it to a catalyst converter. The performance of the Engine depends upon the design of the exhaust manifold. Principally, the efficiency of the emission and fuel utilization are strongly related with the exhaust manifold. The rising and falling temperature causes fatigue due to less thermal efficiency of manifold leading to the fracture. A thorough attention has been determined on the low cycle thermal fatigue by accelerated laboratory tests and by FEM or analytical methods for evaluating life performance of the exhaust manifold under a cyclic thermal loading. Designs that do not add to a smooth flow were very typical in early on. The reverse force built up was a large amount greater than before the work done by the redesigned piston at the exhaust stroke. Huge amount of remaining gases stay in the compression chamber and, as a consequence, the temperature increases. Sometimes when working tough the manifold glow red-hot. The materials used like asbestos, a highly heat withstand able fibrous silicate mineral, to guard paintwork. At the moment, exhaust manifold designs have been distorted totally to get better in comparing with previous configurations, designers have move towards up with altered designs that decrease the flow opposition by using a lot enhanced pipe layout and increasing the average exhaust velocity of the gases, which improve the power output.

\section{Literature Survey}

Gocmez et al. [1] developed a model that Exhaust manifold crack beginning Thermo mechanical Fatigue (TMF) are frequently seen on extremely loaded engines due to rising marketplace difficulty for presentation and emissions. Due to utmost gas temperatures that in a quantity of instance are already above $1000^{\circ} \mathrm{C}$. A variety

of studies are published more than the last few decades concerning the recognition of these critical areas, which comprise taking into account kinematic and isotropic hardening, creep in material modelling and deliberation of plasticity, creep and oxidation in life span modelling. Deger et al.

[2] have analysed the fast advance in simulation technology making it possible to model complex geometrical shapes by using $\mathrm{CAD}$ and material behaviour and load cases to analyze the connected deformations and stresses.

[3] Has analysed lessening of design and development of cycle time can be achieved by sinking the number physical and virtual prototypes. Perceptive the structural performance in the initial phase of design can help to decrease the virtual prototypes in the evaluation time. The engine Exhaust Manifold is a compound system induced to Thermo mechanical loads.

[4] The research article deals with a new method to deal with an Exhaust manifold failure during physical testing on an engine test bed. Rezaei et al. [5] has analysed most of internal combustion engines have multiple heat shields that have been installed on the exhaust manifold to keep away from the heat transfer to upper engine parts, such as the valve cover. In some engines, this part fails due to the fracture and causes engine noise and other failure. In this research the heat shield failure occurs due to engine vibration loads has been analysed by using experimental and FE technique. The results of the optimised heat shield in this field show two of the primary resonance frequencies of heat shield.

Bin zou et al. [6] has analysed the contact of temperature significance on exhaust manifold modal analysis is analyzed in his study. First, the temperature field data are taken from the CFD software and then heat transference process is analyzed in FEM software with the boundary conditions of temperature field. The incident among vibration mode and cold and thermal modals are classified and the results are predicted. The manifold design is influenced by temperature to a greater extent.

\section{Important Parameters}

To design the Exhaust manifold we should consider all the parameters and geometric constraints. The dimensions of the manifold which include the parameters such as length, diameter, and shape essential for a triumphant design. Multiple shapes are 
engaged by using circular and oval pipes in the exhaust manifold design. The advantage of using circular pipes is the increased cross sectional area when compared to Oval pipes thus increasing flow distribution. The manifold pipes can be designed. Angular pipes with higher inclination will amplify the flow resistance. As high speed engines emits more exhaust gases with high speed which requires superior diameters pipes. On the contrary, low speed engines require lower diameter pipes. The pipe length is a critical design criterion as to get better performance in the available space. Long pipes are required to reduce exhaust speed of the exhaust and to expand the gases. Also long pipes reduce residual gases formation inside the cylinder thus improving the power and efficiency of the Engine.

\section{Methodology}

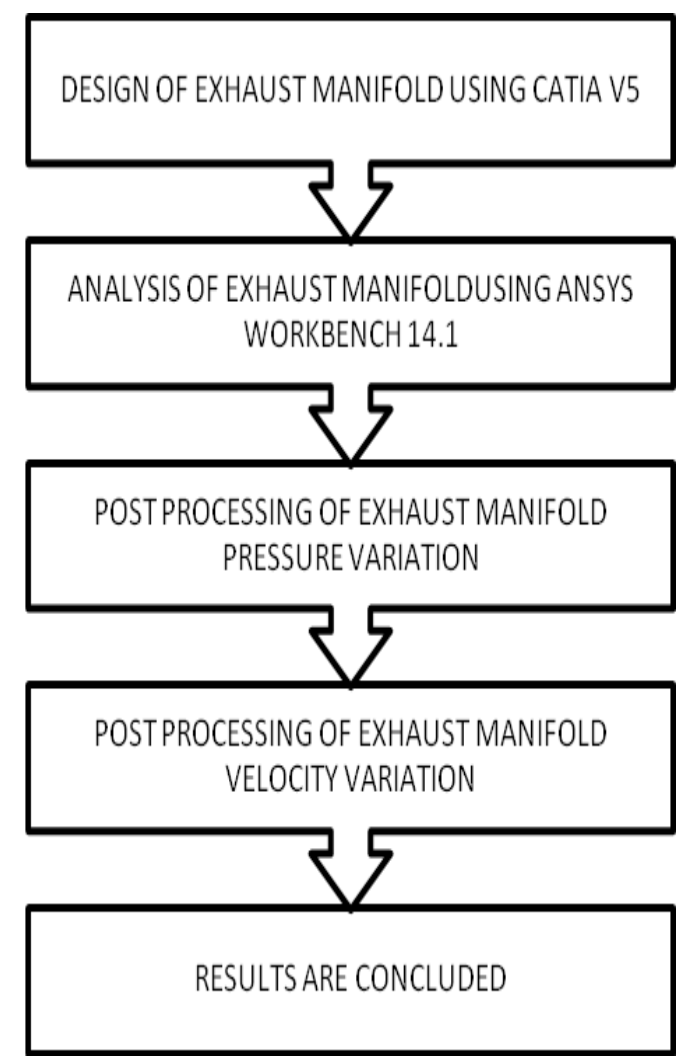

Fig. 4: Methodology

- The analysis of the manifold with the CFD to check the mass flow rate and velocity of the manifold.

- $\quad$ From the CFD results we will gather the thermal results which are taken as the input for the thermal analysis which is steady state thermal analysis or transient type.

- $\quad$ So we will make detail study about the CFD analysis over the exhaust manifold and as well the thermal analysis of the manifold to check the failure of the thermo mechanical on the removal of the structural weakness.

\subsection{Design of Exhaust Manifold}

The following figures 4.1, 4.2, 4.3, 4.4, 4.5 and 4.6 shows the two dimensional and 3 dimensional Exhaust manifold design components.
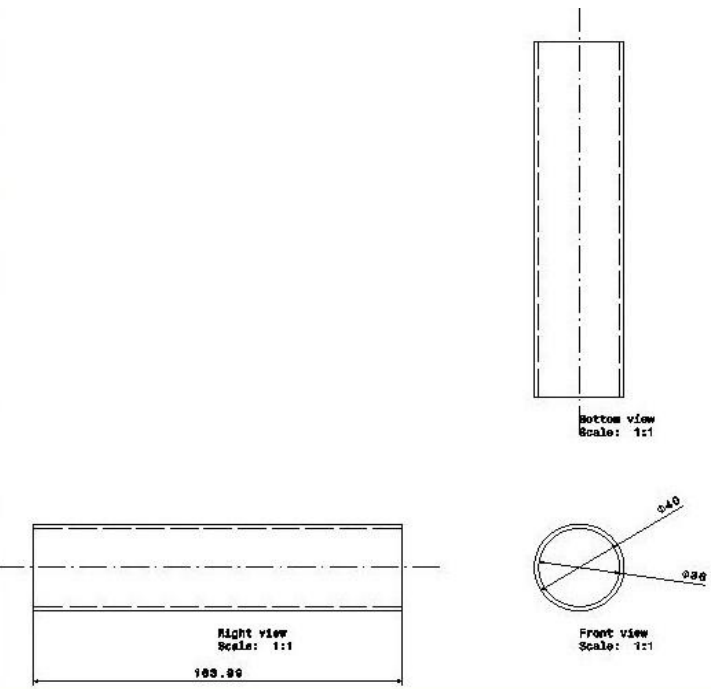

Fropt view

Fig. 4.1: Design of Pipe

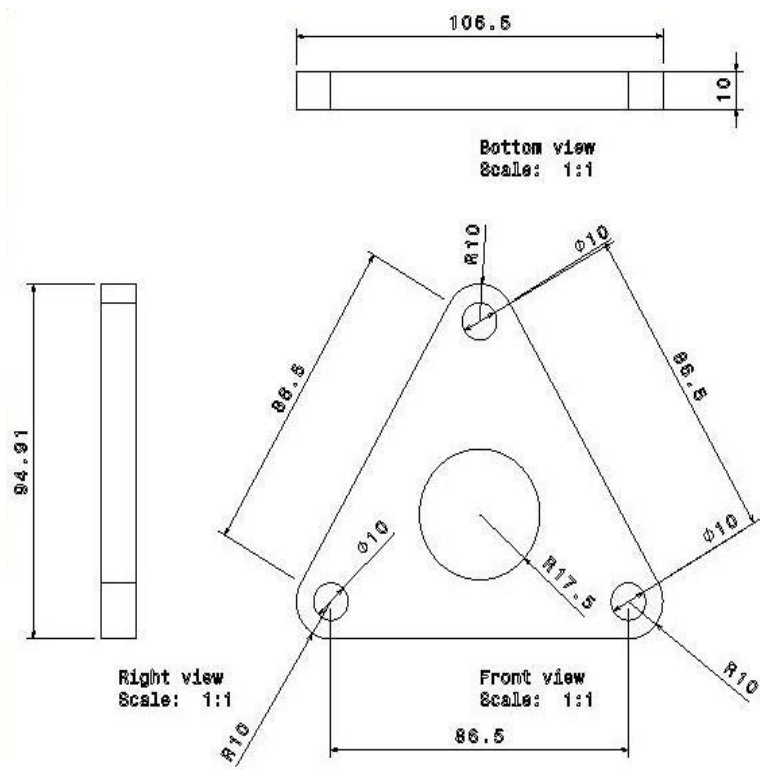

Fig. 4.2: Design of Clamp
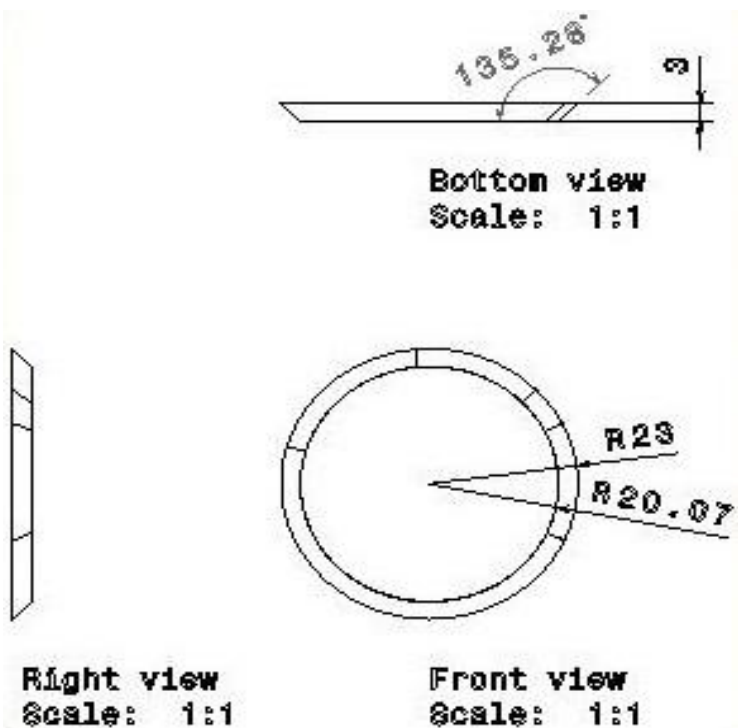

Fight 1 isw
8cgle: $1: 1$

ront visw

Fig. 4.3: Design of Ring 

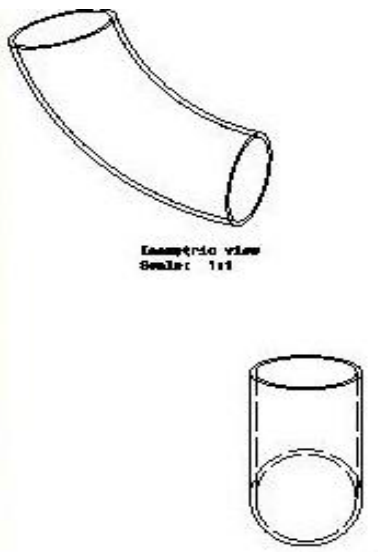

night rew

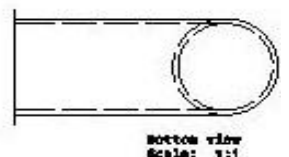

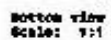

Fig. 4.4: Design of Bend
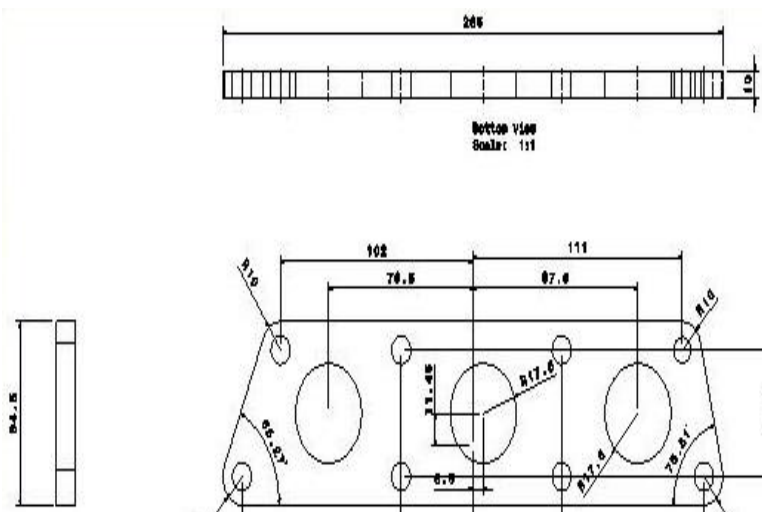

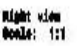

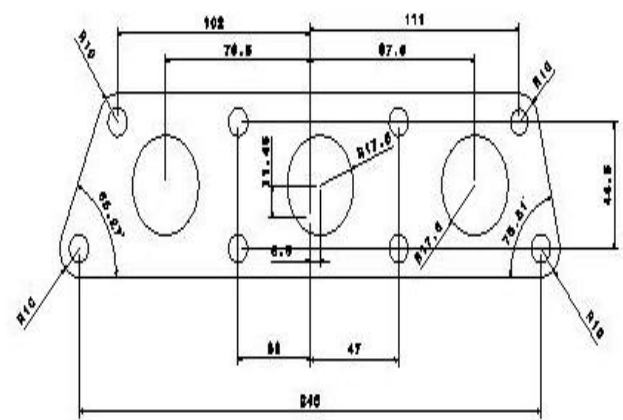

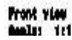

Fig. 4.5: Design of Manifold

\subsection{Design of Exhaust Manifold in CATIA V5}

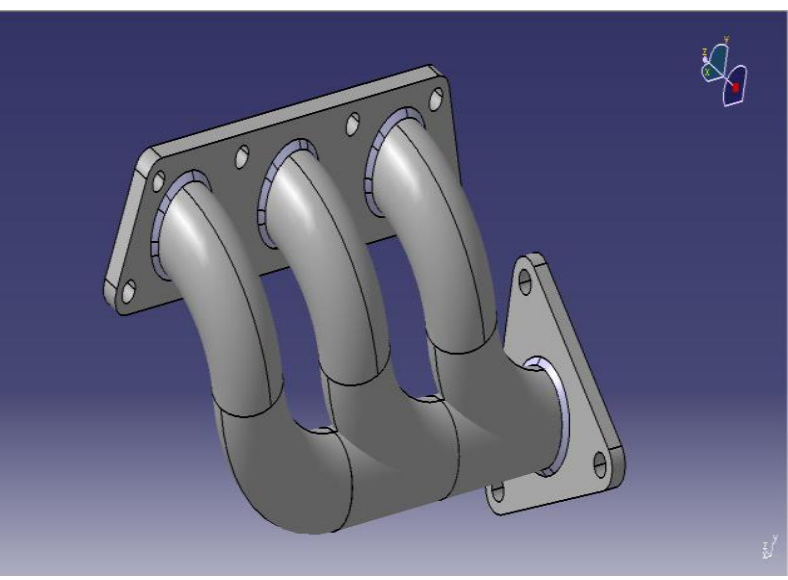

Fig. 4.6: 3D Model of Exhaust Manifold

\subsection{Analysis of Exhaust Manifold}

- In this exhaust manifold, we are using the computational fluid dynamics techniques using ANSYS CFX module to calculate the velocity, pressure drop.

- Setup the boundary conditions for the engine stroke with respect to inlet normal velocity or in terms of mass flow rate and pressure at the exhaust pipe.

\subsection{Inlet Normal Velocity}

- $\quad$ Inlet $1=89.09 \mathrm{~m} / \mathrm{sec}$

- Inlet $2=94.943 \mathrm{~m} / \mathrm{sec}$

- $\quad$ Inlet $3=98.112 \mathrm{~m} / \mathrm{sec}$

- $\quad$ Outlet pressure $=101325 \mathrm{~Pa}$

\subsection{Domain Parameters}

- Domain: Fluid type

- Type of Fluid: NO at STP

- Type of Flow: Continuous Flow

- Fluid Temperature: $600 \mathrm{C}$

- Turbulence Type: K- Epsilon Model

\section{Results and Discussion}

The following figures 5.1 and 5.2 shows the ANSYS results of manifold design

\subsection{Post processing of exhaust manifold pressure} variation

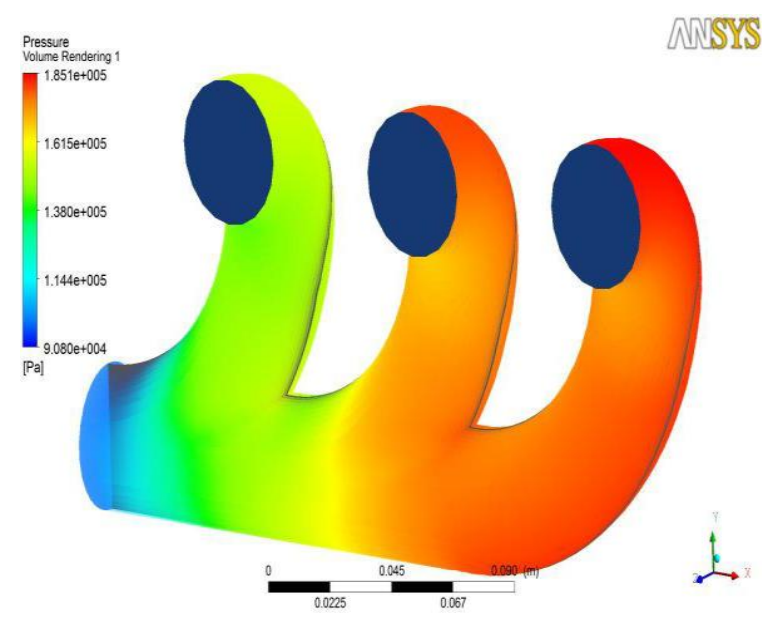

Fig. 5.1: Post processing of exhaust manifold pressure variation

\subsection{Post Processing of Exhaust Manifold Velocity Variation}
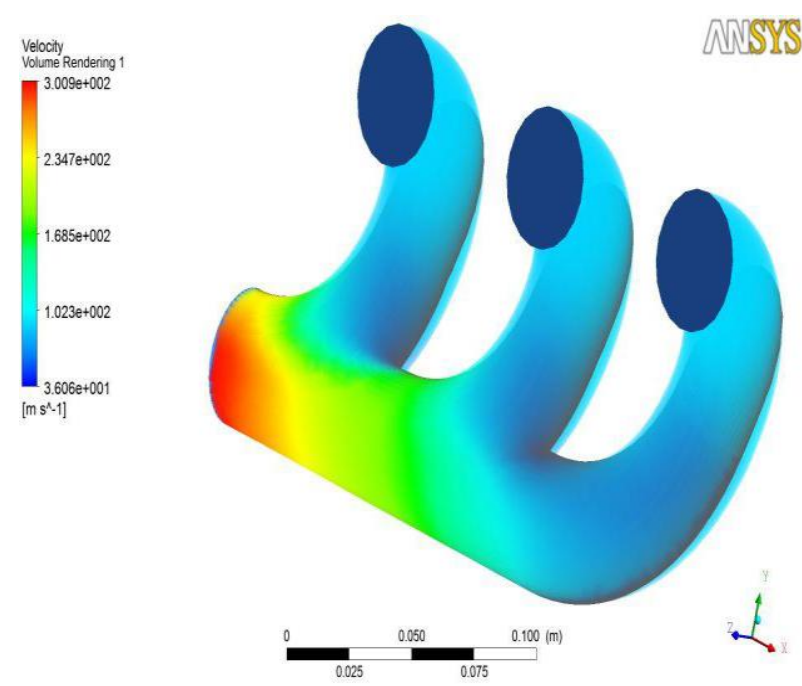

Fig. 5.2: Post Processing of Exhaust Manifold Velocity Variation 


\section{Conclusion}

The research work concludes that due to the inclination angle in the manifold pipe, We can see a pressure drop transversely the outlet exhaust pipe which leads to increase in volumetric efficiency across the manifold and reduce the flow resistance of the fluid causing increase of the engine power and ultimately the engine performance would be improved.

\section{References}

[1] Gocmez, T., Trampert, S., Nagpal, P., Quadflieg, F.-J., "Designing Exhaust Manifolds Using Integral Engineering Solutions", Automobile technische Konferenz, 19.-20.10.2006.

[2] Yasar Deger, Burkhard Simperl, Luis P. Jimenez, "Coupled CFD-FE-Analysis for the Exhaust Manifold of a Diesel Engine", Technical Report Nr. TB03_0123, Sulzer Innotec, Oct. 2009.

[3] Abhijit Londhe, Vivek Yadav, "Thermo-Structural Strength Analysis for Failure Prediction and Concern Resolution of an Exhaust Manifold", International Journal of Solids and Structures, Vol. 8, pp. 69-91, 2008.

[4] Henrik Ekholm, Bjorn Zettervall, "Modal analysis on a Exhaust manifold to define a catalyst FE model", The Journal of Engine Research, Vol. 26 (spring 2012)

[5] Razeai, Experimental and finite element vibrational analysis of exhaust manifold heat shield, The Journal of Engine Research,Vol. 24 (spring 2011).

[6] Bin Zou, Yaqian Hu, Zhien Liu, Fuwu Yan and Chao Wang, "The impact of temperature effect on Exhaust manifold Thermal Modal Analysis", Research Journal of Applied Sciences, Engineering and Technology (15): 2824-2829, 2013.

[7] C Krishnaraj, KM Mohanasundram "Design and implementation study of knowledge based foundry total failure mode effects analysis technique"European Journal of Scientific Research, 2012

[8] T.Padmapriya and V.Saminadan, "Utility based Vertical Handoff Decision Model for LTE-A networks", International Journal of Computer Science and Information Security, ISSN 1947-5500, vol.14, no.11, November 2016.

[9] S.V.Manikanthan and D.Sugandhi "Interference Alignment Techniques For Mimo Multicell Based On Relay Interference Broadcast Channel "International Journal of Emerging Technology in Computer Science \& Electronics (IJETCSE) ISSN: 0976-1353 Volume- 7 ,Issue 1 -MARCH 2014. 